\begin{tabular}{|c|l|}
\hline Title & $\begin{array}{l}\text { Vapour and mechanically induced chromic behaviour of platinum complexes with a dimer-of-dimer motif and the } \\
\text { effects of heterometal ions }\end{array}$ \\
\hline Author(s) & Ohba, Tadashi; Kobay ashi, A tsushi; Chang, Ho-Chol; Kato, Masako \\
\hline Citation & $\begin{array}{l}\text { Dalton Transactions, 42(15),5514-5523 } \\
\text { https://doi.org/40.1039/03dt33100h }\end{array}$ \\
\hline Issue Date & 2013-02 \\
\hline Doc URL & http://hdl.handle.net/2115/54595 \\
\hline Type & article (author version) \\
\hline File Information & OhbaMPt13MK.pdf \\
\hline
\end{tabular}

Instructions for use 


\title{
Vapour and mechanically induced chromic behaviour of platinum complexes with a dimer-of-dimer motif and the effects of hetero metal
} ions

\author{
Tadashi Ohba, Atsushi Kobayashi, Ho-Chol Chang, Masako Kato* \\ ${ }_{5}$ Received (in $\left.X X X, X X X\right)$ Xth $X X X X X X X X X 20 X X$, Accepted Xth $X X X X X X X X X 20 X X$ \\ DOI: $10.1039 / b 000000 x$
}

Heterodinuclear complexes, syn- $\left[\mathrm{MPt}(\mu-\mathrm{pyt})_{2}(\mathrm{bpy})_{2}\right]^{n+}\left(\operatorname{syn}-[\mathbf{M P t}], \mathrm{M}=\mathrm{Pd}^{2+}, \mathrm{Au}^{3+}, \mathrm{Hpyt}=\right.$ pyridine-2thiol, bpy $=2,2^{\prime}$-bipyridine) were synthesized as a selective geometrical isomer by stepwise complexation. $\mathrm{X}$-ray analyses of the hexafluorophosphate salts of these complexes proved their dinuclear structures with 10 short M $\cdots$ Pt distances (2.9084(4) $\AA$ for syn-[PdPt] and 2.9071(4) $\AA$ for syn-[AuPt]), similar to the homodinuclear complex (2.9292(2) $\AA$ for syn-[PtPt]). In the syn-[PdPt] crystal, two dinuclear motifs are arranged closely in a head-to-head manner with a short Pt $\cdots P t$ distance (3.3757(3) $\AA$ ), forming a dimerof-dimer structure as in the case of syn-[PtPt], whereas the corresponding crystal of syn-[AuPt] has a discrete arrangement of the dinuclear motifs. By the isomerisation of syn-[PdPt], anti-[PdPt] with 15 equivalent environments of the $\mathrm{Pd}^{2+}$ and $\mathrm{Pt}^{2+}$ ions was also obtained successfully. Syn- $[\mathbf{P d P t}]\left(\mathrm{PF}_{6}\right)_{2}$ exhibits vapochromic behaviour based on the absorption/desorption of $\mathrm{CH}_{3} \mathrm{CN}$ vapour, similar to that observed for $s y n$ - $[\mathbf{P t P t}]\left(\mathrm{PF}_{6}\right)_{2}$. The reversible structural transformations induced by the uptake and release of $\mathrm{CH}_{3} \mathrm{CN}$ molecules were investigated by powder and single-crystal X-ray diffraction studies. These revealed that the vapochromic behaviour was based on the interconversion between two phases, the 20 dimer-of-dimer structure with a short Pt $\cdots \mathrm{Pt}$ distance and a $\pi-\pi$ stacked arrangement with no Pt $\cdots \mathrm{Pt}$ intermolecular interaction. The introduction of the hetero metal ions enabled control of the colour region: orange $\leftrightarrow$ red for syn-[PdPt] vs. light red $\leftrightarrow$ dark red for syn-[PtPt], reflecting the weaker metal-metal interaction between $\mathrm{Pd}^{2+}$ and $\mathrm{Pt}^{2+}$ ions in the dinuclear motif. In addition, these complexes were found to exhibit mechanochromic behaviour based on a crystal-to-amorphous transformation upon grinding, and

25 the reconstruction of the crystal structures by vapour sorption.

\section{Introduction}

There has been considerable interest in recent years in the development of vapochromic sensor materials for the detection of volatile organic compounds (VOCs). ${ }^{1}$ In particular, assembled 30 platinum(II) complexes with $\mathrm{d}^{8}$ configurations provide rich chromotropic chemistry on the basis of changes in intermolecular interactions such as $\pi-\pi$, donor-acceptor, and metal-metal interactions induced by the absorption/desorption of vapour molecules. ${ }^{2}$ Thus, they are promising materials for naked-eye ${ }_{35}$ perceivable chemosensors for small molecules. However, vapochromic systems with clearly elucidated mechanisms are still limited despite the increasing numbers of reported systems, and detailed investigation is necessary to achieve their rational design.

We previously reported a homometallic dinuclear 40 platinum(II) complex, $\left[\mathrm{Pt}_{2}(\mu-\text { pyt })_{2}(\text { bpy })_{2}\right]^{2+}$ (pyt $=$ pyridine-2thiolate, bpy $=2,2^{\prime}$-bipyridine) ${ }^{3}$ which has two geometrical isomers, the syn- and anti-isomers (syn-[PtPt $]$ and anti-[PtPt $]$, corresponding to the case of $\mathrm{M}=\mathrm{Pt}^{2+}$ in Scheme 1. The hexafluorophosphate salt of syn-[PtPt] exhibits an interesting 45 vapour-induced colour change between dark-red and light-red on the absorption/desorption of acetonitrile $\left(\mathrm{CH}_{3} \mathrm{CN}\right)$ molecules.

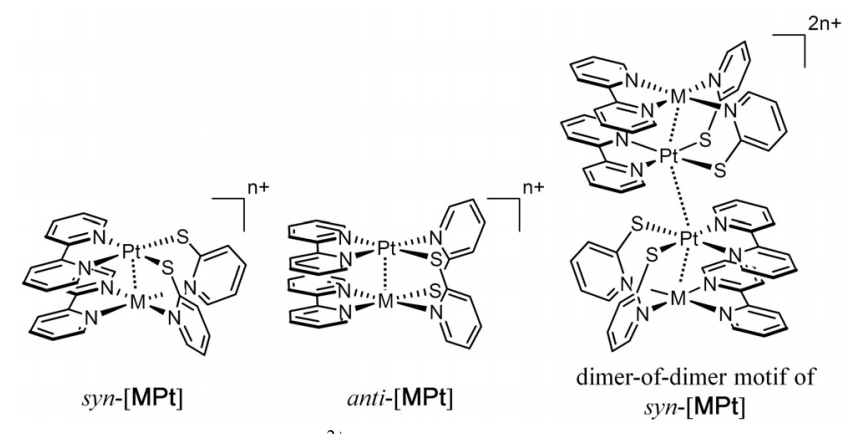

Scheme 1 Homo- $\left(\mathrm{M}=\mathrm{Pt}^{2+}\right)$ and heterodinuclear motifs.

Concomitantly, a remarkable luminescence switching occurs for 50 the dinuclear complex. The dark-red form $\left(\mathrm{CH}_{3} \mathrm{CN}\right.$-included form) of the syn-isomer crystal adopts a dimer-of-dimer structure, wherein the four Pt ions of two syn-[PtPt] cations are arranged so as to generate an intermolecular metal-metal interaction (Scheme 1). Similar dimer-of-dimer structures are known for mixed${ }_{55}$ valence platinum complexes (i.e. platinum blues). ${ }^{4}$ Though there is no chemical bond between intermolecular divalent platinum ions for syn-[PtPt], the expansion of the electronic metal-metal 
interactions from the dimer to the dimer-of-dimer structure could lower the energy of the metal-metal-to-ligand charge transfer (MMLCT) transition. ${ }^{3}$ Thus, we proposed that the vapochromic behaviour for this system would occur by the change of the $\mathrm{Pt} \cdots \mathrm{Pt}$ 5 electronic interactions between the dinuclear complexes. To explore the electronic effects of the metal-metal interactions on the vapochromic behaviour, it would be effective to introduce different metal ions into the same dinuclear motif. Fortunately, the structural features of syn-[PtPt] strongly suggest that the

10 molecular framework would be a good candidate for the incorporation of two different metal ions because the bridging ligand (pyt) provides two different coordination environments.

In this work, we newly synthesized two heterodinuclear metal complexes using $\mathrm{d}^{8}$ metal ions, syn-[MPt $\left.(\mu-\text { pyt })_{2}(\text { bpy })_{2}\right]^{n+}($ syn$\left.15[\mathbf{M P t}] ; \mathrm{M}=\mathrm{Pd}^{2+}(n=2), \mathrm{M}=\mathrm{Au}^{3+}(n=3)\right)$, as well as anti$\left[\operatorname{PdPt}(\mu-p y t)_{2}(\text { bpy })_{2}\right]^{2+}$ (anti-[PdPt $\left.]\right)$. The hexafluorophosphate salt of syn-[PdPt] exhibited vapochromic behaviour with different colour changes from that of syn-[PtPt], while syn[AuPt] and anti-[PdPt] did not show any vapochromic behaviour. ${ }_{20} \mathrm{We}$ also succeeded in the direct observation of the structural transformation induced by the absorption/desorption of vapour molecules for $s y n$-[PtPt] and $s y n-[\mathbf{P d P t}]$ on the basis of X-ray diffraction studies. Herein, the particular mechanism of the vapochromism and the effects of hetero metal ions based on the 25 metal-metal interactions for these dinuclear systems are discussed, considering other findings by UV-vis spectroscopy and thermal analysis.

\section{Experimental}

${ }_{30}$ Materials and synthesis. All starting materials were used as received from commercial sources, and the solvents were used without purification. 2,2'-Bipyridine (bpy), pyridine-2-thiol (Hpyt) and $\mathrm{PdCl}_{2}$ were purchased from Wako. $\mathrm{K}_{2} \mathrm{PtCl}_{4}$ and $\mathrm{HAuCl}_{4}$ were purchased from Tanaka Holdings. $\left[\mathrm{PtCl}_{2}\right.$ (bpy)], $35\left[\mathrm{PdCl}_{2}(\mathrm{bpy})\right],{ }^{6}\left[\mathrm{AuCl}_{2}(\mathrm{bpy})\right]\left(\mathrm{NO}_{3}\right),{ }^{7}\left[\mathrm{Pt}(\mathrm{pyt})_{2}(\mathrm{bpy})\right],{ }^{8}$ and syn$\left[\mathrm{Pt}_{2}(\mu \text {-pyt })_{2}(\mathrm{bpy})_{2}\right]\left(\mathrm{PF}_{6}\right)_{2}{ }^{3}$ were prepared according to methods previously reported.

Syn-[PdPt $\left.(\mu-\mathbf{p y t})_{2}(\mathbf{b p y})_{2}\right]\left(\mathbf{P F}_{\mathbf{6}}\right)_{2} \quad\left(s y n-[\mathbf{P d P t}]\left(\mathrm{PF}_{6}\right)_{2}\right)$. To a suspension of $\left[\mathrm{PdCl}_{2}\right.$ (bpy)] $(33.3 \mathrm{mg}, 0.1 \mathrm{mmol})$ in $\mathrm{H}_{2} \mathrm{O}(6 \mathrm{~mL})$ 40 was added silver nitrate $(34.0 \mathrm{mg}, 0.2 \mathrm{mmol})$ in $\mathrm{H}_{2} \mathrm{O}(4 \mathrm{~mL})$. The reaction mixture was stirred for $2 \mathrm{~h}$ in the dark at $60^{\circ} \mathrm{C}$, and then filtered to remove silver chloride. The pale yellow filtrate was treated with $\left[\mathrm{Pt}(\mathrm{pyt})_{2}\right.$ (bpy)] $(57.1 \mathrm{mg}, 0.1 \mathrm{mmol})$ in $\mathrm{H}_{2} \mathrm{O}(2 \mathrm{~mL})$. The resulting red solution was allowed to stir for $30 \mathrm{~min}$ and ${ }_{45} \mathrm{NH}_{4} \mathrm{PF}_{6}(81.5 \mathrm{mg}, 0.5 \mathrm{mmol})$ in $\mathrm{H}_{2} \mathrm{O}(2 \mathrm{~mL})$ was added. An orange precipitate was immediately deposited, which was then filtered and dried under reduced pressure. Yield: $103.5 \mathrm{mg}$ (92.1\%). Red polyhedral crystals (syn-isomer) suitable for X-ray diffraction were obtained as an $\mathrm{CH}_{3} \mathrm{CN}$-solvated form by the 50 diffusion method using $\mathrm{Et}_{2} \mathrm{O} / \mathrm{CH}_{3} \mathrm{CN}$ at $4{ }^{\circ} \mathrm{C}$. ${ }^{1} \mathrm{H}$ NMR (DMSO$\left.d_{6}\right): \delta 7.30(\mathrm{t}, 2 \mathrm{H}), 7.39(\mathrm{td}, 2 \mathrm{H}), 7.44(\mathrm{~d}, 2 \mathrm{H}), 7.59(\mathrm{t}, 2 \mathrm{H}), 7.69(\mathrm{t}$, $2 \mathrm{H}), 7.82(\mathrm{~d}, 2 \mathrm{H}), 8.15(\mathrm{~d}, 2 \mathrm{H}), 8.18(\mathrm{td}, 2 \mathrm{H}), 8.27(\mathrm{t}, 2 \mathrm{H}), 8.35$ $(\mathrm{d}, 2 \mathrm{H}), 8.87(\mathrm{~d}, 2 \mathrm{H}), 9.07(\mathrm{~d}, 2 \mathrm{H}) . \quad$ Anal. Calcd. for $\mathrm{C}_{30} \mathrm{H}_{24} \mathrm{~F}_{12} \mathrm{~N}_{6} \mathrm{P}_{2} \mathrm{PdPtS}_{2}$ : C, 32.05; H, 2.15; N, 7.48; S, 5.71. Found: ${ }_{55} \mathrm{C}, 32.00 ; \mathrm{H}, 2.26$; N, 7.46; S, 5.87.

Anti-[PdPt $\left.(\mu-\mathbf{p y t})_{\mathbf{2}}(\mathbf{b p y})_{2}\right]\left(\mathbf{P F}_{\mathbf{6}}\right)_{\mathbf{2}} \quad\left(\right.$ anti- $\left.[\mathbf{P d P t}]\left(\mathrm{PF}_{6}\right)_{2}\right)$. The powder of the $s y n$-[PdPt] complex $(98.3 \mathrm{mg}, 87 \mu \mathrm{mol})$ was dissolved in $\mathrm{CH}_{3} \mathrm{CN}(1 \mathrm{~mL})$ and allowed to stand for 1 day at room temperature (RT). After 1 day, a crystal suitable for X-ray ${ }_{60}$ diffraction was obtained as an $\mathrm{CH}_{3} \mathrm{CN}$-solvated form by the

Table 1 Crystallographic data of hexafluorophosphate salts of [MPt]

\begin{tabular}{|c|c|c|c|}
\hline & syn- $[\mathbf{P d P t}]\left(\mathrm{PF}_{6}\right)_{2} \cdot 1.5 \mathrm{CH}_{3} \mathrm{CN}$ & anti-[PdPt $]\left(\mathrm{PF}_{6}\right)_{2} \cdot \mathrm{CH}_{3} \mathrm{CN}$ & syn- $[\mathbf{A u P t}]\left(\mathrm{PF}_{6}\right)_{3} \cdot 2 \mathrm{CH}_{3} \mathrm{CN}$ \\
\hline Formula & $\mathrm{C}_{33} \mathrm{H}_{28.5} \mathrm{~N}_{7.5} \mathrm{~F}_{12} \mathrm{P}_{2} \mathrm{PdPtS}_{2}$ & $\mathrm{C}_{32} \mathrm{H}_{27} \mathrm{~N}_{7} \mathrm{~F}_{12} \mathrm{P}_{2} \mathrm{PdPtS}_{2}$ & $\mathrm{C}_{34} \mathrm{H}_{30} \mathrm{~N}_{8} \mathrm{AuF}_{18} \mathrm{P}_{3} \mathrm{PtS}_{2}$ \\
\hline Formula weight & 1185.68 & 1165.15 & 1441.73 \\
\hline Crystal system & Orthorhombic & Monoclinic & Monoclinic \\
\hline Space group & Pbcn (\#60) & $P 2_{1} / c(\# 14)$ & $C 2 / c(\# 15)$ \\
\hline$a(\AA)$ & $27.586(4)$ & $24.774(2)$ & $22.673(3)$ \\
\hline$b(\AA)$ & $13.543(2)$ & $11.1858(8)$ & $13.050(2)$ \\
\hline$c(\AA)$ & $21.015(3)$ & $14.211(1)$ & $30.037(5)$ \\
\hline$\alpha\left(^{\circ}\right)$ & 90 & 90 & 90 \\
\hline$\beta\left({ }^{\circ}\right)$ & 90 & $92.3480(8)$ & $100.1920(5)$ \\
\hline$\gamma\left({ }^{\circ}\right)$ & 90 & 90 & 90 \\
\hline$V\left(\AA^{3}\right)$ & $7851(2)$ & $3934.7(5)$ & $8747(2)$ \\
\hline$Z$ & 8 & 4 & 8 \\
\hline$T(\mathrm{~K})$ & 150 & 150 & 150 \\
\hline$D_{\text {calcd }}\left(\mathrm{g} \mathrm{cm}^{-3}\right)$ & 2.006 & 1.967 & 2.189 \\
\hline$\mu(\operatorname{Mo} K \alpha)\left(\mathrm{cm}^{-1}\right)$ & 42.87 & 42.74 & 68.66 \\
\hline$R_{1}^{a}\left(F^{2}>2 \sigma\left(F^{2}\right)\right)$ & 0.0605 & 0.0477 & 0.0504 \\
\hline$w R_{2}^{b}$ (all data) & 0.1087 & 0.1186 & 0.1169 \\
\hline
\end{tabular}


diffusion method using $\mathrm{Et}_{2} \mathrm{O} / \mathrm{CH}_{3} \mathrm{CN}$ at RT. Yield: $45.2 \mathrm{mg}$ (46.0\%). ${ }^{1} \mathrm{H}$ NMR (DMSO- $\left.d_{6}\right): \delta 7.21-7.35(\mathrm{~m}, 4 \mathrm{H}), 7.55(\mathrm{~d}, 1 \mathrm{H})$, $7.46(\mathrm{t}, 4 \mathrm{H}), 7.77(\mathrm{t}, 1 \mathrm{H}), 7.90(\mathrm{t}, 1 \mathrm{H}), 8.38(\mathrm{~d}, 2 \mathrm{H}), 8.74(\mathrm{~d}, 2 \mathrm{H})$, 8.83 (d, 2H). Anal. Calcd. for $\mathrm{C}_{30} \mathrm{H}_{24} \mathrm{~F}_{12} \mathrm{~N}_{6} \mathrm{P}_{2} \mathrm{PdPtS}_{2}: \mathrm{C}, 32.05 ; \mathrm{H}$, 5 2.15; N, 7.48. Found: C, 31.83; H, 2.30; N, 7.47.

\section{Syn-[AuPt $\left.(\mu-p y t)_{2}(\text { bpy })_{2}\right]\left(\mathbf{P F}_{6}\right)_{3}$}

(syn-[AuPt $\left.]\left(\mathrm{PF}_{6}\right)_{3}\right)$. $\left[\mathrm{AuCl}_{2}(\mathrm{bpy})\right]\left(\mathrm{NO}_{3}\right)(72.7 \mathrm{mg}, 0.15 \mathrm{mmol})$ was suspended in $\mathrm{H}_{2} \mathrm{O}$ $(10 \mathrm{~mL})$ and silver nitrate $(50.4 \mathrm{mg}, 0.3 \mathrm{mmol})$ in $\mathrm{H}_{2} \mathrm{O}(5 \mathrm{~mL})$ was added. The reaction mixture was stirred for 3 days in the 10 dark at RT and then filtered to remove silver chloride. The pale yellow filtrate was treated with $\left[\mathrm{Pt}(\mathrm{pyt})_{2}(\mathrm{bpy})\right](57.1 \mathrm{mg}, 0.1$ mmol) in $\mathrm{H}_{2} \mathrm{O}(2.5 \mathrm{~mL})$. The resulting solution was stirred for 30 min at room temperature. $\mathrm{NH}_{4} \mathrm{PF}_{6}(81.5 \mathrm{mg}, 0.5 \mathrm{mmol})$ in $\mathrm{H}_{2} \mathrm{O}(2$ $\mathrm{mL}$ ) was added and the resulting red precipitate was filtered. The

15 red filtrate was allowed to stand for ca. 10 days and a red crystalline solid was obtained (yield: $22.6 \mathrm{mg}(17 \%)$ ). Dark red crystals suitable for X-ray diffraction were obtained as an $\mathrm{CH}_{3} \mathrm{CN}$ -solvated form via the diffusion of EtOH into a $\mathrm{CH}_{3} \mathrm{CN}$ solution of the crude material. ${ }^{1} \mathrm{H}$ NMR $\left(\right.$ DMSO- $\left._{6}\right)$ for $20\left[\operatorname{AuPt}(\text { pyt })_{2}(\mathrm{bpy})_{2}\right]\left(\mathrm{PF}_{6}\right)_{3}: \delta 7.45(\mathrm{~m}, 2 \mathrm{H}), 7.70(\mathrm{t}, 2 \mathrm{H}), 7.84(\mathrm{~d}$, $2 \mathrm{H}), 7.86(\mathrm{~d}, 2 \mathrm{H}), 8.11(\mathrm{t}, 2 \mathrm{H}), 8.24(\mathrm{~d}, 2 \mathrm{H}), 8.33(\mathrm{~d}, 4 \mathrm{H}), 8.53(\mathrm{t}$, $2 \mathrm{H}), 8.64(\mathrm{~d}, 2 \mathrm{H}), 9.02(\mathrm{~d}, 2 \mathrm{H}), 9.10(\mathrm{~d}, 2 \mathrm{H})$. Anal. Calcd. for $\mathrm{C}_{30} \mathrm{H}_{24} \mathrm{AuF}_{18} \mathrm{~N}_{6} \mathrm{P}_{3} \mathrm{PtS}_{2}$ : C, 26.50; H, 1.78; N, 6.18; S, 4.72. Found: C, 26.38; H. 1.90; N, 5.92; S, 4.67 .

\section{Physical measurements}

${ }^{1} \mathrm{H}$ NMR spectra were recorded on a JEOL JNM-EX270 FTNMR system. Elemental analyses were performed by a Micro Corder JM 10 analyser at the Analysis Centre, Hokkaido 30 University. UV-vis spectra in solution were recorded on a Shimadzu MultiSpec-1500 spectrophotometer. UV-vis diffuse reflectance spectra were obtained on a Hitachi U-3000 spectrometer equipped with an integrating sphere apparatus. Thermogravimetry and differential thermal analysis were 35 performed using a Rigaku ThermoEvo TG8120 analyzer.

\section{X-ray diffraction measurements and structure analyses}

A summary of the crystallographic data of the single-crystal Xray diffraction for the syn-[PdPt], anti-[PdPt], and syn-[AuPt] 40 complexes is given in Table 1. Each crystal was mounted on a glass fibre with silicon grease. All measurements for the three crystals were made on a Rigaku AFC-7R diffractometer with Mercury $\mathrm{CCD}$ area detector, graphite monochromated Mo- $\mathrm{K \alpha}$ radiation $(\lambda=0.71069 \AA)$ and a rotating anode generator. The 45 data were corrected for Lorentz and polarization effects. Diffraction data were collected and processed using CrystalClear. ${ }^{9}$ The structures were solved using direct methods $\left(\right.$ SIR92) ${ }^{10}$ and expanded using Fourier techniques (DIRDIF99). ${ }^{11}$ Full-matrix least-squares structural refinement based on $F^{2}$ was 50 employed. The non-hydrogen atoms were refined anisotropically. The hydrogen atoms were refined using a riding model. For anti[PdPt], the Pt and Pd atoms were found to be completely disordered. They were placed on same site at each of the two metal centres with a half occupancy, and their positions were 55 refined. All calculations were performed using CrystalStructure, ${ }^{12}$ a crystallographic software package except for refinement, which was performed using SHELXL97. ${ }^{13}$ Full crystallographic data have been deposited with the Cambridge Crystallographic
Data Centre (CCDC 917078-917080)

Single-crystal to single-crystal transformation for syn-[PtPt] was performed on a Rigaku AFC-8 diffractometer equipped with the nitrogen gas flow variable temperature controller. The data reduction and structure analysis were carried out in a similar manner described above. The crystallographic details are ${ }_{65}$ summarized in the supplementary information.

Powder X-ray diffraction measurements were carried out with $\mathrm{Cu} K \alpha$ radiation using a Rigaku SmartLab diffractometer.

\section{Results and discussion}

Regioselective synthesis of heterodinuclear complexes. We previously reported the one-step synthesis of homodinuclear platinum complexes syn- and anti-[PtPt $]$ by the reaction of $\left[\mathrm{PtCl}_{2}(\mathrm{bpy})\right]$ and $\mathrm{Hpyt}^{3}{ }^{3}$ The syn and anti geometrical isomers were produced as a mixture and the isolation of the syn isomer of 75 the minor component was troublesome in this method. For the regioselective synthesis of the syn isomer, a stepwise complexation as shown in Scheme 2 should be favourable, in particular, it should be a good way to prepare heterodinuclear complexes. Recently, Lippert et al. reported that the stepwise 80 synthesis of a syn isomer of heterodinuclear complex of $\mathrm{Pd}(\mathrm{en})$ (en = ethylenediamine) and Pt(bpy) units by using two cytosinato bridges. However, they could not obtained the corresponding heterodinuclear complex from $\mathrm{Pd}(\mathrm{bpy})$ and $\mathrm{Pt}(\mathrm{bpy})$ units but a Pd-Pt-Pd trinuclear motif with an anti-configration. ${ }^{14} \mathrm{We}$ 85 succeeded in the formation of the syn isomer of heterodinucler complex comprising $\mathrm{Pd}(\mathrm{bpy})$ and $\mathrm{Pt}(\mathrm{bpy})$ units by using the pyt bridging ligand. The different affinities of the coordinating atoms ( $\mathrm{N}$ and $\mathrm{S}$ ) in the pyt ligand to $\mathrm{Pd}^{2+}$ and $\mathrm{Pt}^{2+}$ ions would be more advantageous for the regioselective synthesis. In the first step, the 90 mononuclear complex $\left[\mathrm{Pt}(\mathrm{pyt})_{2}(\mathrm{bpy})\right]$ including S-coordinated pyt ligands was selectively prepared. In the second step, the $\mathrm{Pd}^{2+}$ ion was introduced by the coordination of nitrogen atoms of the pyt ligands. Applying this stepwise synthesis, the syn-[AuPt] complex was also obtained.

95 In solution at room temperature, the isomerisation from syn- to anti-isomer is very slow for [PtPt]. In the case of the palladiumplatinum mixed complex, [PdPt], however, the isomerization was faster than that for the dinuclear platinum complex, and syn[PdPt] was almost completely converted to anti-[PdPt] within a 100 day at RT (Fig. S1). The crystal of anti-[PdPt] was thus isolated from the solution. On the other hand, isomerization of syn-[AuPt] was not observed, but a precipitate due to decomposition was deposited after one day in $\mathrm{CH}_{3} \mathrm{CN}$.

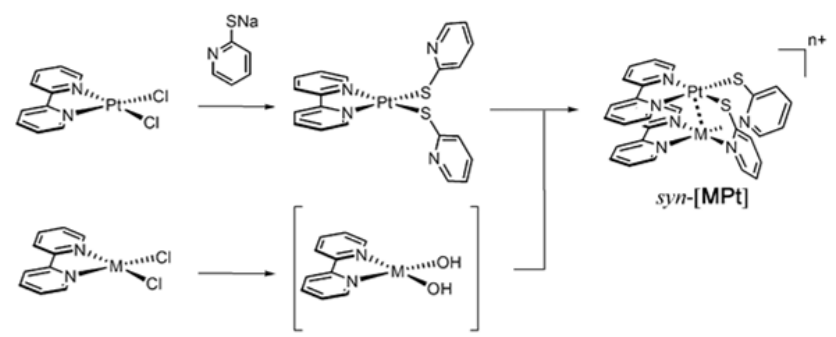

105 Scheme 2 Regioselective synthesis of syn-[MPt] motif. 

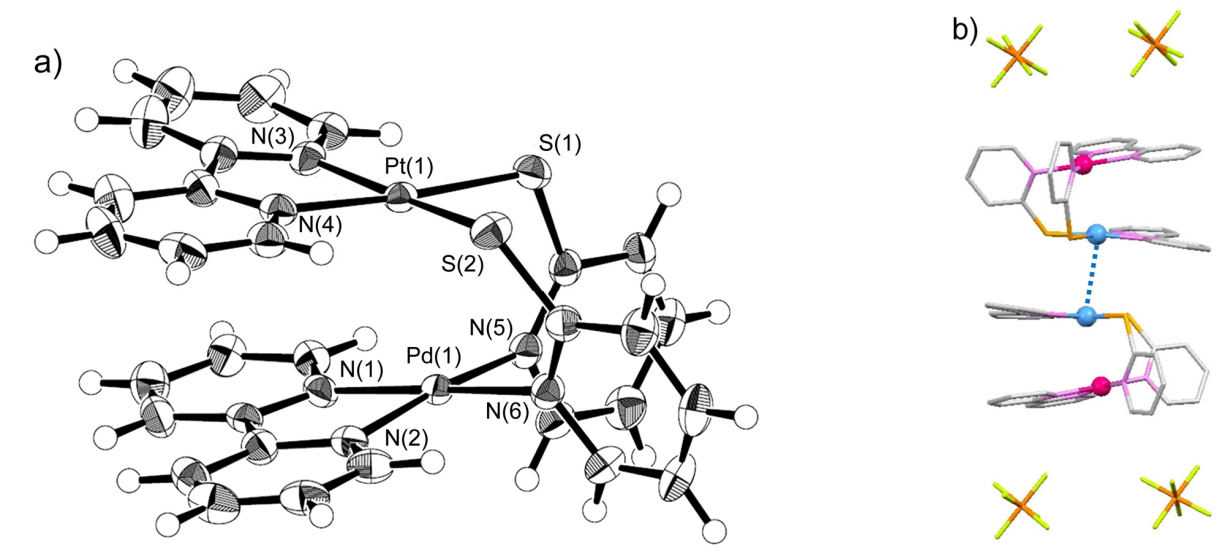

Fig. 1 a) Molecular structure of syn-[PdPt] (50\% probability ellipsoids). b) The dimer-of-dimer structure of $\operatorname{syn}$-[PdPt]. The $\mathrm{PF}_{6}^{-}$ions located at the top and bottom of the dimer-of-dimer motif are also included. The intermolecular Pt $\cdots$ Pt contact is shown by the dotted line.
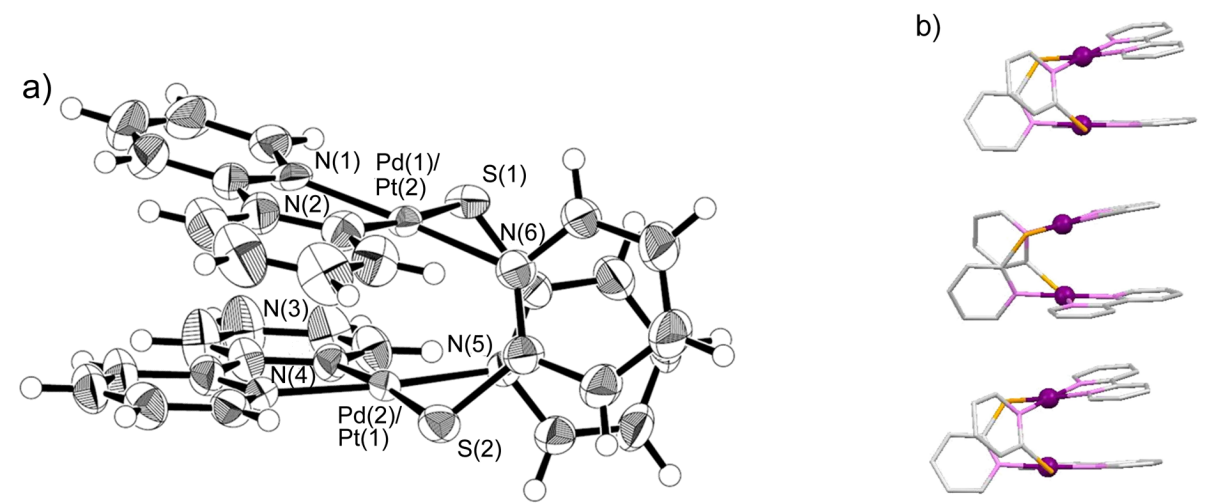

Fig. 2 a) Molecular structure of anti-[PdPt] (50\% probability ellipsoids). The Pt and Pd atoms are disordered with half occupancies. b) The loose stacked structure of anti-[PdPt].

a)

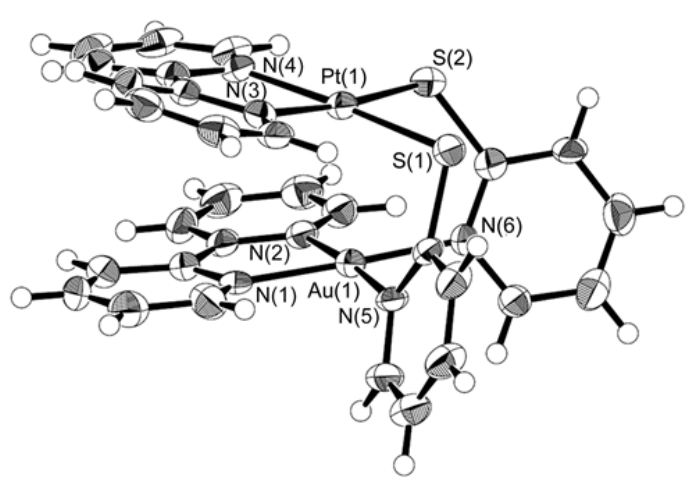

b)

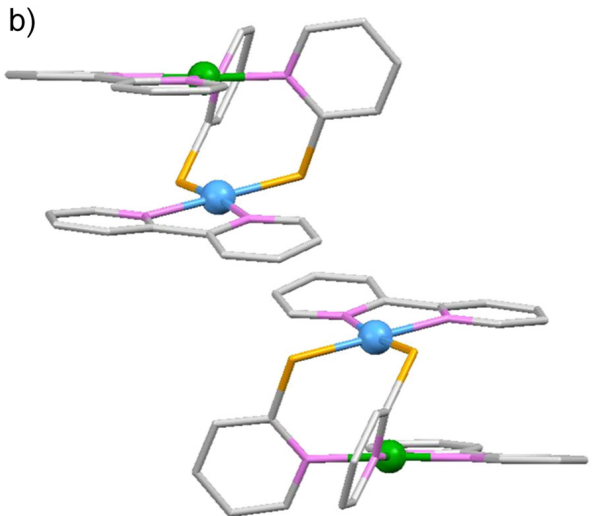

Fig. 3 a) Molecular structure of syn-[AuPt] (50\% probability ellipsoids). b) No interactive arrangement of two adjacent complexes for syn-[AuPt].

Crystal structures. Figs. 1, 2, and 3 show the structures of syn-[PdPt], anti-[PdPt], and syn-[AuPt] in the $\mathrm{CH}_{3} \mathrm{CN}$-included forms of the hexafluorophosphates, respectively. The selected interatomic distances and dihedral angles are shown in Table 2 as 5 well as those of syn-[PtPt]. The hexafluorophosphate salt of syn$[\mathbf{P d P t}]$ was found to be isostructural with that of $s y n-[\mathbf{P t P t}] .^{3}$ As shown in Fig. 1a, the $\mathrm{Pd}^{2+}$ ion in syn-[PdPt] was surrounded by four nitrogen atoms while the $\mathrm{Pt}^{2+}$ ion was coordinated by two nitrogen atoms and two sulphur atoms. Reasonable values for the 10 thermal factors for Pt and Pd supported the assignment in this structure, indicating no disorder between the two metal ions.
Observed Pd-N, Pt-S, and Pt-N bond distances are typical values. The dihedral angle between the Pd-bpy and Pt-bpy planes (the least-square planes defined by the metal ion and non-hydrogen 15 atoms of the bpy ligand) is about $14^{\circ}$ which is similar to that of syn-[PtPt]. The intramolecular Pd $\cdots P t$ distance $(2.9084(4) \AA)$ is also comparable to that of the syn-[PtPt] complex (2.9168(3) $\AA$ ), and shorter than the sum of the van der Waals radii of Pt and Pd (3.38 $\AA$ ), suggesting that a metal-metal interaction is in effect in 20 the heterodinuclear complex. Interestingly, two syn-[PdPt] units were arranged so that the Pt ions are closely located, as shown in Fig. 1b. This dimer-of-dimer structure is nearly the same as that 
Table 2 Selected interatomic distances $(\AA)$ and dihedral angles $\left(^{\circ}\right)$ for three $s y n-[\mathbf{M P t}]\left(\mathrm{PF}_{6}\right)_{\mathrm{n}} \operatorname{complexes}$ and anti- $[\mathbf{P d P t}]\left(\mathrm{PF}_{6}\right)_{2}$.

\begin{tabular}{|c|c|c|c|c|}
\hline & syn- $[\mathbf{P t P t}]\left(\mathrm{PF}_{6}\right)_{2}{ }^{a}$ & $s y n-[\mathbf{P d P t}]\left(\mathrm{PF}_{6}\right)_{2}$ & syn- $[\mathbf{A u P t}]\left(\mathrm{PF}_{6}\right)_{3}$ & anti- $[\mathbf{P d P t}]\left(\mathrm{PF}_{6}\right)_{2}$ \\
\hline Selected distance $(\AA)$ & $\mathrm{M}=\mathrm{Pt}$ & $\mathrm{M}=\mathrm{Pd}$ & $\mathrm{M}=\mathrm{Au}$ & $\mathrm{M}=\mathrm{Pd}$ \\
\hline $\mathrm{Pt}-\mathrm{S}$ & $2.281(2), 2.291(2)$ & $2.293(2), 2.282(2)$ & $2.299(2), 2.318(2)$ & $2.297(2), 2.309(2)$ \\
\hline $\mathrm{Pt}-\mathrm{N}(\mathrm{bpy})$ & $2.062(7), 2.076(6)$ & $2.070(5), 2.060(5)$ & $2.099(5), 2.097(5)$ & $2.018(6), 2.045(6)$ \\
\hline M-N(bpy) & $2.010(6), 2.033(6)$ & $2.023(5), 2.012(5)$ & $2.016(5), 2.024(5)$ & $2.058(6), 2.026(5)$ \\
\hline $\mathrm{M}-\mathrm{N}(\mathrm{pyt})$ & $2.027(5), 2.040(6)$ & $2.040(5), 2.034(5)$ & $2.029(5), 2.030(5)$ & $2.023(5), 2.032(5)$ \\
\hline $\mathrm{M} \cdots \mathrm{Pt}$ (intramolecular) & $2.9168(3)$ & $2.9084(4)$ & $2.9292(3)$ & $2.9767(5)$ \\
\hline $\mathrm{Pt} \cdots \mathrm{Pt}$ (intermolecular) & $3.384(1)$ & $3.3757(3)$ & $5.1899(3)$ & $4.2893(3)$ \\
\hline \multicolumn{5}{|l|}{ Dihedral angles $\left({ }^{\circ}\right)$} \\
\hline bpy(M)/bpy(Pt) & $14.22(8)$ & $14.54(6)$ & $13.93(7)$ & $13.3(1)$ \\
\hline bpy $(\mathrm{Pt}) / \mathrm{pyt}$ & $71.7(2), 88.3(1)$ & 71.9(1), 88.1(1) & $72.9(1), 81.0(1)$ & $65.5(1), 71.1(1)$ \\
\hline bpy(M)/pyt & 79.4(1), 98.3(1) & $79.9(1), 98.06(8)$ & $67.1(1), 70.8(1)$ & 74.3(1), 72.1(1) \\
\hline
\end{tabular}

of syn-[PtPt]. The intermolecular distance between the two Pt ions for syn-[PdPt] $(3.3757(3) \AA)$ is shorter than twice the van der Waals radius of $\mathrm{Pt}(3.50 \AA)$, as in the case of syn-[PtPt] $(3.384(1) \AA),{ }^{3}$ strongly suggesting a metal-metal interaction 5 between two $s y n$-[PdPt]. Interestingly, a dimer-of-dimer structure for $\left[\mathrm{PtPd}(\mathrm{bpy})_{2}(\mathrm{DMGI})_{2}\right](\mathrm{DMGI}=3,3$-dimethylglutarimidate $)$ adopted an arrangement which faced two $\mathrm{Pd}^{2+}$ coordination sites instead of the $\mathrm{Pt}^{2+}$ sites, and the $\mathrm{Pd} \cdots \mathrm{Pd}$ distance was very long (3.829(2) $\AA$ ), suggesting no intermolecular metal-metal 10 interaction. $^{15}$

Figure 2 depicts the structure of anti-[PdPt]. Each metal ion is surrounded by three nitrogen atoms and one sulphur atom. In contrast with syn-[PdPt], the Pt and Pd ions for anti-[PdPt] were found to be completely disordered at the two metal sites. The 15 heterodinuclear structure was confirmed by the FAB-MS spectrum of the crystalline sample which gave only the peaks originating from the heterodinuclear complex [PdPt] $(\mathrm{m} / \mathrm{z}=$ 977.1 for $\left\{[\mathbf{P d P t}] \cdot \mathrm{PF}_{6}\right\}^{+}$, Fig. S2). The intramolecular $\mathrm{Pd} \cdots \mathrm{Pt}$ distance for anti-[PdPt] was 2.9765(3) $\AA$, which also suggests 20 the existence of a metal-metal interaction, although it is slightly longer than that of syn-[PdPt]. Considering that the torsion angle between the bpy ligands about the Pd-Pt axis (N1-M $\cdots \mathrm{M}^{\prime}-\mathrm{N} 3=$ $40.3^{\circ}$ av.) is much larger for anti-[PdPt] than for syn-[PdPt] (N1$\mathrm{Pd} \cdots \mathrm{Pt}-\mathrm{N} 3=17.8^{\circ}$ av.), as well as the smaller dihedral angles 25 between the bpy and pyt ligands for anti-[PdPt] than for syn[PdPt] (Table 2), the longer Pd $\cdots P t$ distance of anti-[PdPt] is attributable to the larger deformation of the dinuclear framework compared with that of syn-[PdPt]. In the crystal, anti-[PdPt] forms a columnar structure with intermolecular $\pi$ - $\pi$ stacking $30(3.35 \AA$ ) between the bpy ligands (Fig. 2b), in which the stack is a rather shifted arrangement to avoid the steric hindrance of the pyt ligand. The deformation of the dinuclear framework in anti[PdPt] could be due to adjustment of the packing structure. As a result, the intermolecular metal-metal distance $(4.3 \AA)$ in the 35 column is too long for a metal-metal interaction.

Figure 3a shows the molecular structure of syn-[AuPt]. As in the case of syn-[PdPt], the introduced $\mathrm{Au}^{3+}$ ion occupies the $\mathrm{N}_{4}$ coordination site while the $\mathrm{Pt}$ ion is coordinated by two sulphur and two nitrogen atoms. The intramolecular $\mathrm{Au} \cdots \mathrm{Pt}$ distance

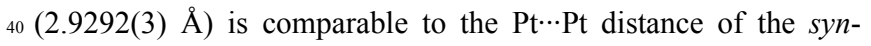

[PtPt] complex and shorter than the sum of the van der Waals radii $(3.41 \AA)$, suggesting that a metal-metal interaction is in effect in the $\mathrm{Pt}(\mathrm{II})-\mathrm{Au}(\mathrm{III})$ dinuclear complex. Although the stacking structure of $\mathrm{Pt}^{2+}$ and monovalent $\mathrm{Au}^{+}$ions is well 45 known, ${ }^{16}$ assembled systems of $\mathrm{Au}(\mathrm{III})$ complexes have not often been reported. The dimeric structure of $\left[\mathrm{Au}\left(\mathrm{C}^{\wedge} \mathrm{N}^{\wedge} \mathrm{N}-\mathrm{dpp}\right) \mathrm{Cl}\right]^{+}$ $\left(\mathrm{C}^{\wedge} \mathrm{N}^{\wedge} \mathrm{N}\right.$-dppH $=$ 2,9-diphenyl-1,10-phenanthroline) was reported to provide a long $\mathrm{Au} \cdots \mathrm{Au}$ distance $(3.6 \AA) .{ }^{17} \mathrm{~A} \pi-\pi$ stacking structure was found for a $\mathrm{Au}(\mathrm{III})$ complex, ${ }_{50}\left[\mathrm{Au}\left(\mathrm{C}^{\wedge} \mathrm{N}^{\wedge} \mathrm{C}\right)(\mathrm{C} \equiv \mathrm{CPh})\right] \quad\left(\mathrm{HC}^{\wedge} \mathrm{N}^{\wedge} \mathrm{CH}=\right.$ 2,6-diphenylpyridine $)$, where $\mathrm{Au} \cdots \mathrm{Au}$ was 5.003(1) $\AA .{ }^{18}$ Bosnich et al. reported that the interaction between $\mathrm{Pt}^{2+}$ and $\mathrm{Au}^{3+}$ was unfavourable on the basis of experiments carried out for the adduct formation of a $\mathrm{Pt}(\mathrm{II})$ dinuclear complex with a terpyridine derivative, and a $\mathrm{Au}(\mathrm{III})$ ${ }_{55}$ complex, $\left[\mathrm{Au}\left(\mathrm{C}^{\wedge} \mathrm{N}^{\wedge} \mathrm{C}\right) \mathrm{CN}\right] .{ }^{19}$ To the best of our knowledge, syn[AuPt] is the first example that includes $\mathrm{Au}^{3+}$ and $\mathrm{Pt}^{2+}$ ions in close arrangement. The key point for syn-[AuPt] is that no intermolecular interactions could be observed between adjacent dinuclear complexes $(\mathrm{Pt} \cdots \mathrm{Pt}=5.1899(3) \AA)$ in contrast to the ${ }_{60}$ cases for syn-[PdPt] and syn-[PtPt] (Fig. 3b). This is due to the higher positive charge $(3+)$ of syn-[AuPt]. There are three $\mathrm{PF}_{6}^{-}$ anions per one $[\mathbf{A u P t}]$ cation in the crystal, which prevents the complexes from forming the dimer-of-dimer structure with a short intermolecular Pt $\cdots \mathrm{Pt}$ contact.

65

Vapochromic behaviour. The syn-[PdPt $]$ salt exhibits vapochromic behaviour, similarly to the isomorphous syn-[PtPt] salt. Characteristically, syn-[PdPt] exhibited a quite different colour change compared with the syn-[PtPt] salt (Fig. 4). For 70 syn-[PdPt], the $\mathrm{CH}_{3} \mathrm{CN}$-included form is red in colour and airstable at room temperature (Fig. 4A). However, a colour change from red to orange was observed upon moderate heating $\left(50^{\circ} \mathrm{C}\right)$ under dry Ar atmosphere or vacuum (Fig. 4B). Upon exposure to $\mathrm{CH}_{3} \mathrm{CN}$ vapour, the orange colour reverted to the original red 75 colour in a few minutes. Such colour changes occurred reversibly by the absorption and desorption of $\mathrm{CH}_{3} \mathrm{CN}$ vapour as proven by an adsorption isotherm and thermogravimetric analyses for syn[PdPt] (Figs. S3 and S4). The absence of $\mathrm{CH}_{3} \mathrm{CN}$ molecules in the orange form was also confirmed by ${ }^{1} \mathrm{H}$ NMR measurements 80 (Fig. S5). For comparison of the vapour response of the syn- 


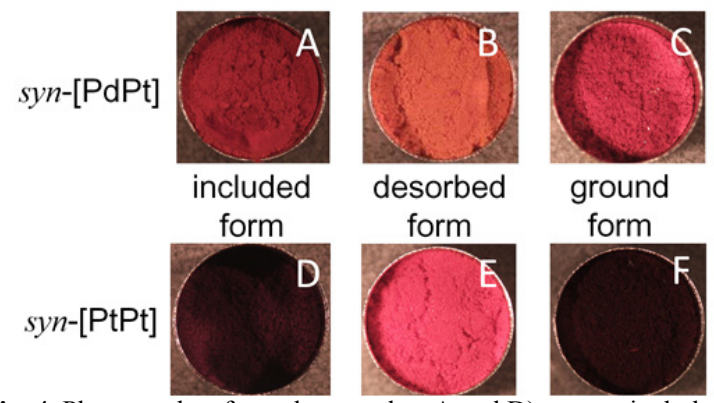

Fig. 4 Photographs of powder samples: A and D) vapour-included forms; $\mathrm{B}$ and $\mathrm{E}$ ) desorbed forms; and $\mathrm{C}$ and $\mathrm{F}$ ) ground forms, for syn-[PdPt] and syn-[PtPt $]$, respectively.

[MPt] complexes, UV-vis diffuse reflectance spectra of the solid samples are shown in Fig. 5. For both syn-[PdPt] and syn-[PtPt] salts, distinct spectral changes were confirmed on exposure of the samples after heat treatment to $\mathrm{CH}_{3} \mathrm{CN}$ vapour (Figs. 5a and 5b). 5 In contrast, the syn-[AuPt] salt exhibits no chromic behaviour and the solid state spectrum is essentially the same as that in solution (Fig. 5c). The blue-shifted spectra of the desorbed forms for the $s y n$-[PdPt $]$ and $s y n$ - $[\mathbf{P t P t}]$ salts are close to those in solution. Considering the short intermolecular Pt $\cdots \mathrm{Pt}$ distances 10 for the $\mathrm{CH}_{3} \mathrm{CN}$-included forms in the syn-[PdPt] and syn-[PtPt$]$ salts (ca. $3.37 \AA$ ), the red-shifts for the vapour-included forms were attributable to the lowering of the MMLCT transition energy due to the intermolecular Pt $\cdots \mathrm{Pt}$ interactions between the two dinuclear motifs. The conceptual MO energy diagram is

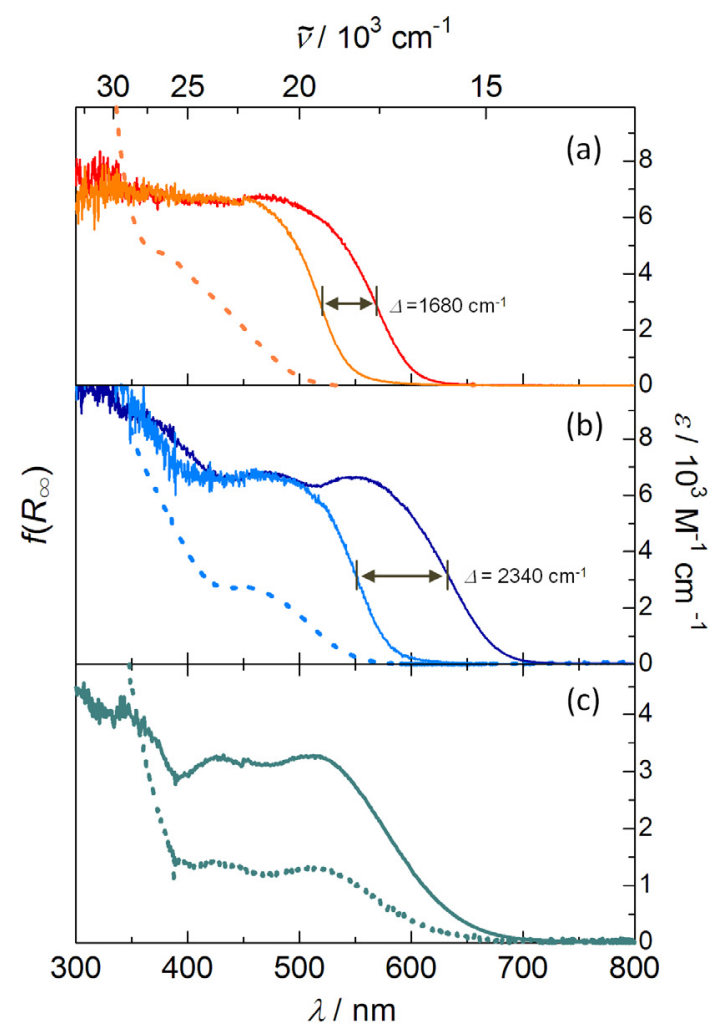

Fig. 5 Diffuse reflectance spectra for hexaflurophosphate of (a) syn-[PdPt], (b) syn-[PtPt], and (c) syn-[AuPt]: orange and light blue solid lines are for the desorbed forms, B and E in Fig. 4, and red blue, and blue solid lines are those under exposure to $\mathrm{CH}_{3} \mathrm{CN}$ vapour, respectively. The dotted lines exhibit the solution spectra in $\mathrm{CH}_{3} \mathrm{CN}$ with the scale on the right.
15 shown in Scheme 3. It is also interesting to note that the spectral change for the syn-[PdPt] salt occurs in a high-energy region compared with that of the $s y n$-[PtPt $]$ salt. This indicates that the chromic region is controlled by the intramolecular metal-metal interaction. Additionally, taking into account that the 20 vapochromic shift is larger for $\operatorname{syn}$-[PtPt $]\left(\Delta=2,340 \mathrm{~cm}^{-1}\right)$ than for $\operatorname{syn}$-[PdPt] $\left(\Delta=1,680 \mathrm{~cm}^{-1}\right)$, where $\Delta$ denotes the energy difference in wavenumbers of the vapour-included and desorbed spectra at the positions with half intensity, the intramolecular metal-metal interaction could affect the intermolecular metal-

25 metal interaction. The influence of the outer metal site on the intermolecular Pt $\cdots \mathrm{Pt}$ interaction was also suggested by the series of corresponding syn-[CuPt] systems bearing different axial ligands on the $\mathrm{Cu}(\mathrm{II})$ site. $^{20}$

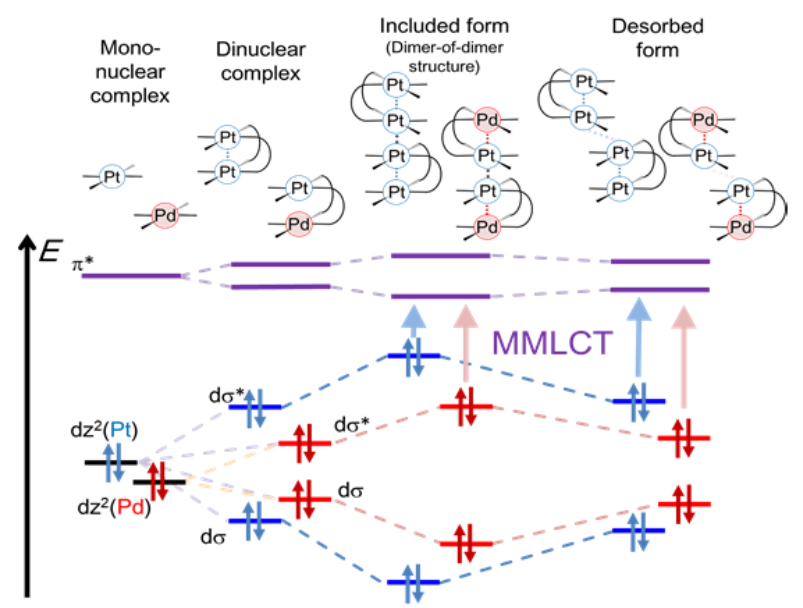

Scheme 3 Conceptual MO energy diagram for syn-[PdPt] and syn[PtPt].

30 Structural transformation induced by vapour. To clarify the structural factors of the colour change induced by the absorption/desorption of vapour molecules, we next carried out single-crystal diffraction measurements at various temperatures. Figure 6 shows the changes in the lattice constants of the dark-red 35 form of syn-[PtPt] with increasing temperature from $-180^{\circ} \mathrm{C}$ under nitrogen gas flow. A drastic change in the lattice parameters occurred at $0^{\circ} \mathrm{C}$ while retaining the same orthorhombic crystal system. Concomitantly, a clear colour change in the crystal was also observed from dark-red to light-red

40 (Fig. 6, inset photos). By using a thus-obtained single crystal of the light-red form, we succeeded in determining the crystal structure of the light-red form. Though the quality of the diffraction data for the light-red form was not very high, it was sufficient to determine the arrangement of the light-red form of 45 syn-[PtPt $]$. As a result, a significantly shifted arrangement of the dimer-of-dimer structure was elucidated (Fig. 7 and Fig. S6). For the light-red form, the intermolecular Pt $\cdots \mathrm{Pt}$ contact that has been observed in the crystal of the dark-red form is completely broken and replaces by the $\pi-\pi$ stacking of the bpy ligands. Although the ${ }_{50}$ dimer structure of the complex unit was essentially the same for both forms, the intramolecular Pt $\cdots$ Pt distance (2.876(2) $\AA$ ) is slightly shorter compared to that of the dark-red form (2.9168(3) $\AA$ ), which could be due to the breaking of the intermolecular $\mathrm{Pt} \cdots \mathrm{Pt}$ interaction $(\mathrm{Pt} \cdots \mathrm{Pt}$ (intermolecular) $=5.508(2) \AA)$. The 


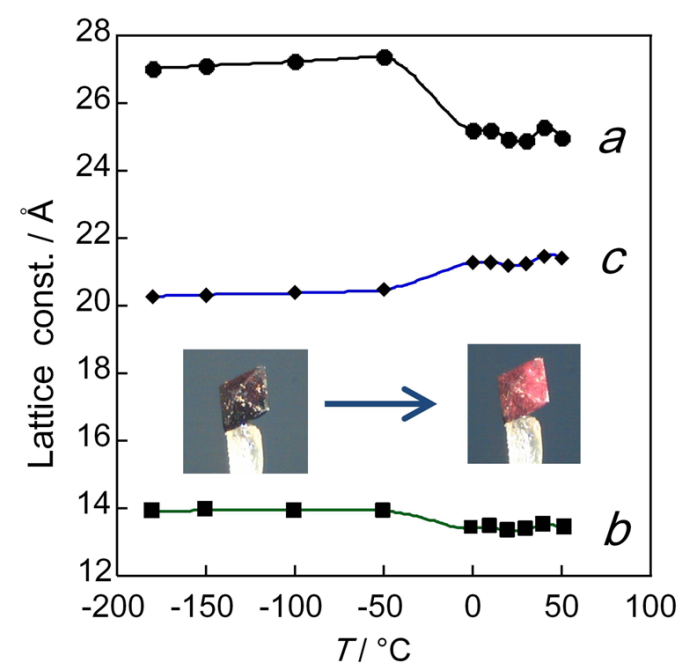

Fig. 6 Plots of the lattice constants $(a, b$, and $c)$ of $s y n$ - $[\mathbf{P t P t}]\left(\mathrm{PF}_{6}\right)_{2}$ $1.5 \mathrm{CH}_{3} \mathrm{CN}$ at various temperatures upon heating from -180 to $50^{\circ} \mathrm{C}$. Inset: Photographs of the sample crystal before and after a series of measurements.
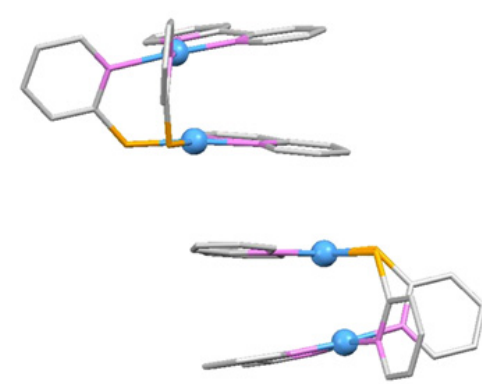

Fig. 7 Shifted dimer-of-dimer structure for the light-red form of syn-[PtPt]. The nearest Pt $\cdots$ Pt distance between the two dinuclear units is 5.508(2) $\AA$.

transformation of the dimer-of-dimer structure is induced by the release of $\mathrm{CH}_{3} \mathrm{CN}$ molecules included in the dark-red form, followed by sliding so as to fill the void space.

5 The reversible structural transformations driving the vapochromic behaviours of syn-[PtPt] and syn-[PdPt] were confirmed by powder X-ray diffraction (PXRD). As shown in Fig. 8 , the PXRD pattern of syn-[PtPt] changed between the vapourincluded and desorbed forms repeatedly, corresponding to the 10 changes in the diffuse reflectance spectra upon repeated heating at $50^{\circ} \mathrm{C}$ and $\mathrm{CH}_{3} \mathrm{CN}$ vapour exposure. Essentially the same changes of the PXRD pattern as those for syn-[PtPt] were observed for the isomorphous syn-[PdPt] (Fig. S7). These results clearly indicate that the vapochromism of syn-[PtPt] and syn-

15 [PdPt] occurs essentially by the same mechanism, which is based on the structural transformation of the intermolecular $\mathrm{Pt} \cdots \mathrm{Pt}$ interaction between the dinuclear units, i.e. an ON-OFF switch. The fact that syn-[AuPt], which lacked the dimer-of-dimer structure, exhibited no vapochromic behaviour also supports this 20 mechanism.

In addition, we investigated the responses of $s y n$-[PdPt] and syn-[PtPt] to other organic vapours. As shown in Fig. 9, similar
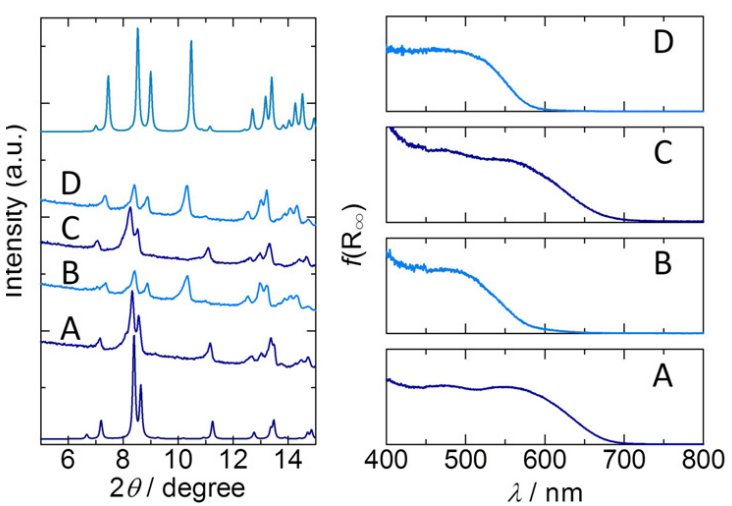

Fig. 8 Reversible vapochromic response of syn-[PtPt]. Left: The PXRD pattern changes in the repeated cycles of $\mathrm{CH}_{3} \mathrm{CN}$ vapour exposure (A and C) and after heating at $80^{\circ} \mathrm{C}$ (B and D). Top and bottom patterns are the calculated ones on the basis of the singlecrystal structures of the light-red and dark-red forms, respectively. Right: The diffuse reflectance spectra of the samples corresponding to the PXRD data.

spectral changes were observed on exposure to vapours of small organic molecules such as methanol, acetone, tetrahydrofuran 25 (THF), and formaldehyde, while no changes occurred for vapours with relatively lower polarity, such as chloroform, $n$-hexane, and carbon tetrachloride. The samples which underwent colour changes by the former vapours exhibited the PXRD patterns of the vapour-included forms (Fig. S8). These results suggest that 30 the structural transformations due to vapour sorption of these complexes generated essentially the same dimer-of-dimer structure with short Pt $\cdots \mathrm{Pt}$ contacts as that found for the $\mathrm{CH}_{3} \mathrm{CN}$ vapour. On the other hand, there are no changes in the PXRD patterns of the desorbed forms in the cases of hexane and carbon 35 tetrachloride vapours. It is interesting to note that some structural transformation occurred in the presence of chloroform vapour, resulting in another structure with no Pt $\cdots$ Pt close contact

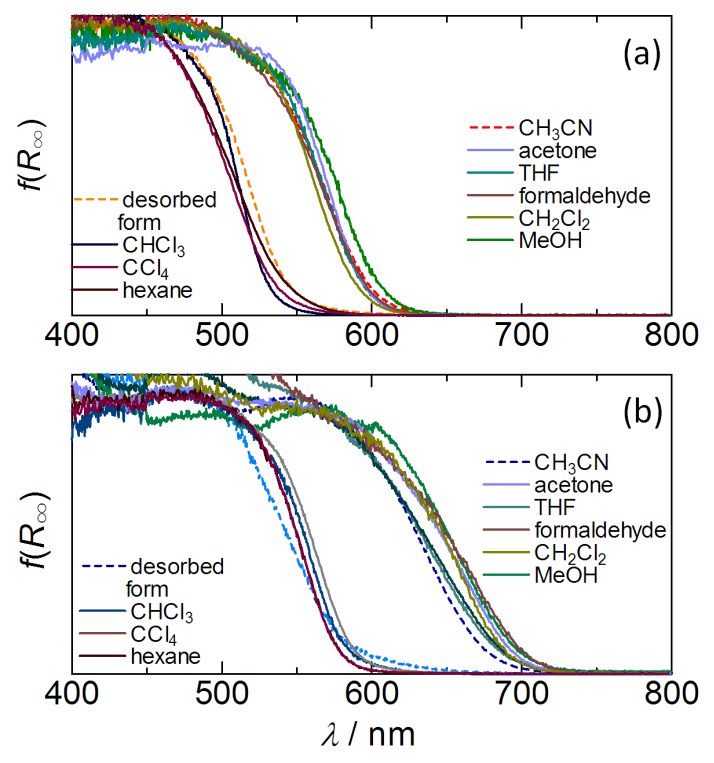

Fig. 9 Diffuse reflectance spectra for (a) syn-[PdPt] and (b) syn[PtPt] under various solvent vapours. 
between the dinuclear motifs. These results suggest that the vapochromic response of these complexes depends on whether the dimer-of-dimer structure with the Pt...Pt close contact can be formed by taking up the vapour. Such vapochromic dinuclear 5 systems are quite unique; most vapochromic systems consist of mononuclear complexes assembled by metallophilic interactions. Only a few examples of dinuclear complexes whose chromic origins are $\pi-\pi$ interactions and halogens have been reported. ${ }^{2 m-o}$

Mechanochromic behaviour. In the course of the 10 investigation of the vapochromic response, we also found that the complexes exhibited mechanochromic behaviour. The desorbed forms of $s y n$-[PtPt] and $s y n$-[PdPt] are air-stable at room temperature. However, when they were ground in agate mortars, distinct colour changes occurred even in the absence of vapour,

15 from orange to red for $s y n$-[PdPt], and from light-red to dark-red for syn-[PtPt] (Figs. 4C and 4F, respectively). The diffuse reflectance spectra of the ground samples exhibited large red shifts compared with those of the desorbed forms, extending to slightly longer wavelengths than those of the corresponding 20 vapour-included forms (Fig. S9). The samples after grinding did not exhibit any diffraction peaks (Fig. S10), indicating that the desorbed crystalline forms of $s y n$-[PtPt] and $s y n$-[PdPt] were transformed to amorphous forms by grinding. The amorphous states were also obtained by grinding the vapour-included forms. ${ }_{25}$ Such mechanochromic behaviours based on a crystalline-toamorphous transformation by grinding were reported recently. ${ }^{21}$ For example, Ito et al. $^{21 a}$ found that the $\mathrm{Au}(\mathrm{I})$ complex, $\left[\left(\mathrm{C}_{6} \mathrm{~F}_{5} \mathrm{Au}\right)_{2}(\mu\right.$-1,4-diisocyanobenzene $\left.)\right] \quad$ exhibited mechanochromic luminescence due to the formation of a $\mathrm{Au} \cdots \mathrm{Au}$ 30 interaction by grinding, and Chen et al. ${ }^{21 b}$ reported the case of platinum(II) complexes containing 5-trimethylsilylethynyl-2,2'bipyridine and phenylacetylide. We also reported a coordination polymer with the formula $\left[\mathrm{Mg}\left(\mathrm{H}_{2} \mathrm{O}\right)_{5}\right]\left[\mathrm{Pt}(\mathrm{CN})_{2}\left(4,4^{\prime}\right.\right.$-dcbpy) (4,4'-dcbpy $=4,4^{\prime}$-dicarboxy-2,2'-bipyridine) which exhibited 35 multichromic behaviour by grinding and vapour exposure. ${ }^{2 i}$ These results suggest that metal-metal interactions often occur in the amorphous state by grinding, forming short, local metal-metal contacts. Interestingly, the vapour-included forms were reconstructed on exposure to $\mathrm{CH}_{3} \mathrm{CN}$ vapour, as shown by the 40 recovered PXRD patterns and absorption spectra for both syn[PdPt $]$ and syn-[PtPt] systems (Fig. S10). Therefore, taking into account the relatively stable dinuclear framework of syn-[MPt] in the solid, it would be reasonable that the intermolecular $\mathrm{Pt} \cdots \mathrm{Pt}$ interaction between the dinuclear motifs could also occur 45 mechanically by the collapse of the crystal structure. It is noteworthy that structural reconstruction was not observed by heating to $50^{\circ} \mathrm{C}$, at which the structural transformations occurred from the included to the desorbed forms. This indicates that vapour molecules play an essential role to control the structural so construction and transformation.

\section{Conclusion}

In addition to homometallic platinum dinuclear complexes bridged by pyridinethiolate ligands, we synthesized a series of ${ }_{55}$ heterodinuclear complexes by stepwise complexation. The mechanism of the vapochromism characteristic of syn$[\mathbf{P d P t}]\left(\mathrm{PF}_{6}\right)_{2}$ and $s y n$-[PtPt $]\left(\mathrm{PF}_{6}\right)_{2}$ was clarified on the basis of $\mathrm{X}$ ray diffraction studies, including a single-crystal to single-crystal transformation and powder diffraction. The vapochromic ${ }_{60}$ behaviour arises by the formation and breaking of the intermolecular Pt $\cdots$ Pt interaction induced by the absorption and desorption of the vapour molecules. It is noteworthy that the energy region of the colour change can be controlled by the introduction of different metal ions, from red to orange for syn${ }_{65}[\mathbf{P d P t}]$ and from dark-red to light-red for syn-[PtPt]. The vapochromic mechanism was also supported by the facts that neither syn-[AuPt] having a discrete dimer structure nor anti[PdPt] with only loose stacking exhibited such vapochromic responses. Furthermore, these complexes were found to exhibit 70 mechanochromic behaviour, through the crystal-to-amorphous transformation, by grinding. The overall chromic behaviour of these dinuclear complexes is summarized in Scheme 4.

The dinuclear complexes constructed using a planar ligand (bpy) and two bridging ligands containing two different 75 coordinating atoms (pyt) constituted a good molecular motif through which to assemble metal ions and control both intra- and intermolecular metal-metal interactions. Taking advantage of the regioselective introduction of the heterometal ions into the same molecular motif, further investigations of syn-[MPt] complexes 80 including $3 \mathrm{~d}$ metal ions are now in progress.

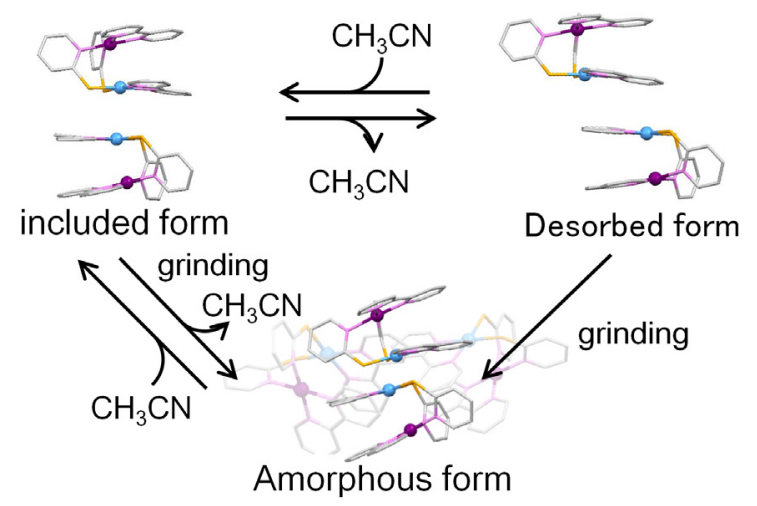

Scheme 4 Structural transformations of the dimer-of-dimer motif of syn-[MPt] $\left(\mathrm{M}=\mathrm{Pd}^{2+}\right.$ and $\left.\mathrm{Pt}^{2+}\right)$ induced by vapour and grinding.

\section{Acknowledgements}

M. K. is grateful to Ms. Y. Wakamatsu for her experimental assistance. This work was supported by a Grant-in-Aid for ${ }_{85}$ Scientific Research (B) (23350025) and Priority Area 'Coordination Programming' (Area No. 2107), and the Elements Science and Technology Project 'Nano-hybridized Preciousmetal-free Catalysts for Chemical Energy Conversion' from the Ministry of Education, Culture, Sports, Science and Technology 90 (MEXT), Japan.

\section{Notes and references}

Department of Chemistry, Faculty of Science, Hokkaido University, North-10 West-8, Kita-ku, Sapporo, Hokkaido 060-0810, Japan. Fax: +81-11-7063447; Tel: +81-11-7063817; E-mail:

95 mkato@sci.hokudai.ac.jp

$\dagger$ Electronic Supplementary Information (ESI) available: ${ }^{1} \mathrm{H}$ NMR spectral changes showing the isomerisation from syn-[PdPt] to anti[PdPt]; FAB-MS spectrum of anti-[PdPt]; vapour-adsorbed isotherm and thermogravimetric curves of $s y n-[\mathbf{P d P t}]\left(\mathrm{PF}_{6}\right)_{2}$; the crystallographic data 
and the structure of the light-red form of $s y n-[\mathbf{P t P t}]\left(\mathrm{PF}_{6}\right)_{2} ; \mathrm{PXRD}$ patterns for syn-[PdPt] and syn-[PtPt] under various vapours; diffuse reflectance spectra and PXRD results for the ground samples of syn-[PdPt] and syn[PtPt]. See DOI: 10.1039/b000000x/

51 (a) X. Zhang, B. Ki, Z.-H. Chen, and Z.-N. Chen, J. Mater. Chem., 2012, 22, 11427; (b) M. A. Moansour, W. B. Connick, R. J. Lachicotte, H. J. Grysling, and R. Eisenberg, J. Am. Chem. Soc. 1998, 120, 1329; (c) E. Cariati, X. Bu, and P. C. Ford, Chem. Mater., 2000, 12, 3385; (d) L. G. Beauvais, M. P. Shores, and J. R. Long, J. Am,

10 Chem. Soc., 2000, 122, 2763; (e) E. J. Fernandez, J. M. Lopez-deLuzuriaga, M. Monge, M. E. Olomos, R. C. Puelles, A. Laguna, A. A. Mohamed, and J. P. Fackler, Inorg. Chem., 2008, 47, 8069; $(f)$ M. Albrecht, M. Lutz, A. L. Spek, and G. Koten, Nature, 2000, 406, 970; (g) A. Kobayashi, M. Dosen, M. Chang, K. Nakajima, S. Noro, and M. Kato, J. Am. Chem. Soc., 2010, 132, 15286; (h) Z. Fri, N. Koche, C. J. Mohrschladt, H. Ihmels, and D. Stalke, Angew. Chem. Int. Ed., 2003, 42, 783; (i) T. Hinoue, M. Miyata, I. Hisaki, and N. Tohnai, Angew. Chem. Int. Ed., 2012, 51, 155.

2 (a) M. Kato, Bull. Chem. Soc. Jpn., 2007, 8, 287; (b) S. M. Drew, D.

20 E. Janzen, C. E. Buss, D. I. MacEwan, K. M. Dublin, and K. R. Mann, J. Am. Chem. Soc., 2001, 123, 8418; (c) T. J. Wadas, Q.-M. Wang, Y. J. Kim, C. Flaschenreim, T. N. Blaton, and R. Eisenberg, J. Am. Chem. Soc., 2004, 126, 16841; (d) L. J. Grove, J. M. Rennekamp, H Jude, and W. B. Connick, J. Am. Chem. Soc., 2004, 126, 1594; (e) M.

25 L. Muro, C. A. Daws, and F. N. Castellano, Chem. Commun., 2008 6134; $(f)$ A. Kobayashi, Y. Fukuzawa, H.-C. Chang, and M. Kato, Inorg. Chem., 2012, 51, 7508; (g) Z. M. Hudson, C. Sun, K. J. Harris, B. E. G. Lucier, R. W. Schurko, and S. Wang, Inorg. Chem., 2011, 50, 3447; (h) J. Ni, Y.-H. Wu, X. Zhang, B. Li, L.-Y. Zhang, and Z.-

30 N. Chen, Inorg. Chem., 2009, 48, 10202; (i) A. Kobayashi, H. Hara T. Yonemura, H.-C. Chang, and M. Kato, Dalton. Trans., 2012, 41, 1878; (j) A. Kobayashi, H. Hara, S. Noro, and M. Kato, Dalton Trans., 2010, 39, 3400; (k) H. Hara, A. Kobayashi, S. Noro, H.-C. Chang, and M. Kato, Dalton. Trans., 2011, 40, 8012; (l) P. Du, J. Schneider, W. W. Brennessel, and R. Eisenberg, Inorg. Chem., 2008 , 47, 69; (m) I. Mathew, Y. Li, Z. Li, and W. Sun, Dalton. Trans., 2010, 39, 11201; (n) S. C. F. Kui, S. S.-Y.Chui, C.-M Che, and N. Zhu, J. Am. Chem. Soc., 2006, 128, 8297; (o) H. Mastuzaki, H. Kishida, H. Okamoto, K. Takizawa, S. Matsunaga, S. Takaishi, H. Miyasaka, K. Sugiura and M. Yamashita, Angew. Chem., Int. Ed., 2005, 44, 3240.

3 M. Kato, A. Omura, A. Toshikawa, S. Kishi, and Y. Sugimoto, Angew. Chem. Int. Ed., 2002, 41, 3183.

4 (a) J. K. Barton, H. N. Rabinowitz, D. J. Szalda, and S. J. Lippard, J Am. Chem. Soc., 1977, 99, 2827; (b) J. P. Laurent, P. Lepage, and F.

45 Dahan, J. Am. Chem. Soc., 1982, 104, 7335; (c) L. S. Hollis and S. J. Lippard, J. Am, Chem. Soc., 1981, 103, 1230; (d) K. Matsumoto and M. Ochiai, Coord. Chem. Rev., 2002, 231, 229; (e) K. Sakai, M. Takeshita, Y. Tanaka, T. Ue, M. Yanagisawa, M. Kosaka, T. Tsubomura, M. Ato, and T. Nakano, J. Am. Chem. Soc., 1998, 120, 11353.

5 T. J. Egan, K. R. Koch, P. L. Swan, C. Clarkson, D. A. V. Schalkwyk, and P. J. Smith, J. Med. Chem., 2004, 47, 2926.

6 M. Noskowska, E. Śliwińska, and W. Duczmal, Transition Met Chem., 2003, 28, 756.

557 J. K. Bjernemose, P. R. Raithby, and H. Toftlund, Acta Cryst., 2004, E60, m1719.

8 B.-C. Tzeng, W.-F Fu, C.-M. Che, H.-Y. Chao, K.-K. Cheung, and S.-M. Peng, J. Chem. Soc., Dalton Trans., 1999, 1017.

9 CrystalClear, Molecular Structure Corporation, Orem, UT, 2001.

6010 SIR92: A. Altomare, G. Cascarano, C. Giacovazzo, A. Guagliardi, M. Burla, G. Polidori, and M. Camalli, J. Appl. Cryst., 1994, 27, 435.

11 DIRDIF99, P. T. Beurskens, G. Admiraal, G. Beurskens, W. P. Bosman, R. de Gelder, R. Israel, and J. M. M. Smits (1999).

12 CrystalStructure 3.8, Crystal Structure Analysis Package, Rigaku and

65 Rigaku/MSC (2000-2006), 9009 New Trails Dr., The Woodlands, TX 77381 USA

13 SHELX97, G. M. Sheldrick, Acta Crystallogr., Sect. A, 2008, 64, 112.

14 L. Yin, P. J. S. Miguel, W. Hiller, and B. Lippert, Inorg. Chem., $2012, \mathbf{5 1}, 6784$

7015 K. Matsumoto, and H. Urata, Chem. Lett., 1993, 2061.
16 (a) R. Hayoun, D. K. Zhong, A. L. Rheingold, and L. H. Doerrer, Inorg. Chem. 2006, 45, 6120; (b) L. H. Doerrer, Dalton Trans., 2010, 39, 3543; (c) M. Stender, R. L. White-Morris, M. M. Olmstead, and A. L. Balch, Inorg. Chem., 2003, 42, 4504.

7517 C.-W. Chan, W.-T. Wong, and C.-M. Che, Inorg. Chem., 1994, 33, 1266.

18 V. W.-W. Yam, K. M.-C. Wong, L.-L. Hung, and N. Zhu, Angew. Chem. Int. Ed., 2005, 44, 3107.

19 J. D. Crowley, and B. Bosnich, Inorg. Chem., 2005, 44, 2989.

${ }_{80} 20$ T. Ohba, A. Kobayashi, H.-C. Chang, and M. Kato, to be submitted.

21 (a) Y. Sagara, and T. Kato, Nature Chem., 2009, 1, 605; (b) Y.-A. Lee, and R. Eisenberg, J. Am. Chem. Soc., 2003, 125, 7778; (c) B. R. Crenshaw, and C. Weder, Chem. Mater., 2003, 15, 4717; (d) Y. Sagara, T. Mutai, I. Yoshikawa, and K. Araki, J. Am. Chem. Soc., 2007, 129, 1520; (e) Y. Sagara, T. Kato, Angew. Chem. Int. Ed., 2008, 47, 5175; (f) G. Zhang, J. Lu, M. Sabat, and C. L. Fraser, J. Am. Chem. Soc., 2010, 132, 2160; ( $g$ ) M. Osawa, I. Kawata, S. Igawa, M. Hoshino, T. Fukunaga, and D. Hashizume, Chem. Eur. J., 2010, 16, 12114; (h) A. Abedi, N. Safari, V. Amani, and H. R. Khavasi, Dalton Trans., 2011, 40, 6877; (i) G. Zhang, J. Lu, and C. L. Fraser, Inorg. Chem., 2010, 49, 10747; (j) Y. Ren, W. H. Kan, V. Thangdfurai, and T. Baumgartner, Angew. Chem. Int. Ed., 2012, 51, 3964.

21 (a) H. Ito, T. Saito, N. Oshima, N. Kitamura, S. Ishizaka, Y. Hinatsu, M. Wakeshima, M. Kato, K. Tsuge, and M. Sawamura, J. Am. Chem. Soc., 2008, 130, 10044; (b) J. Ni, X. Zhang, N. Qiu, Y.-H. Wu, L.-Y. Zhang, J. Zhang, and Z.-N. Chen, Inorg. Chem., 2011, 50, 9090; (c) Y. Sagara, T. Mutai, I. Yoshikawa, and K. Araki, J. Am. Chem. Soc., 2007, 129, 1520; (d) M. Osawa, I. Kawata, S. Igawa, M. Hoshino, T. Fukunaga, and D. Hashizume, Chem. Eur. J., 2010, 16, 12114 